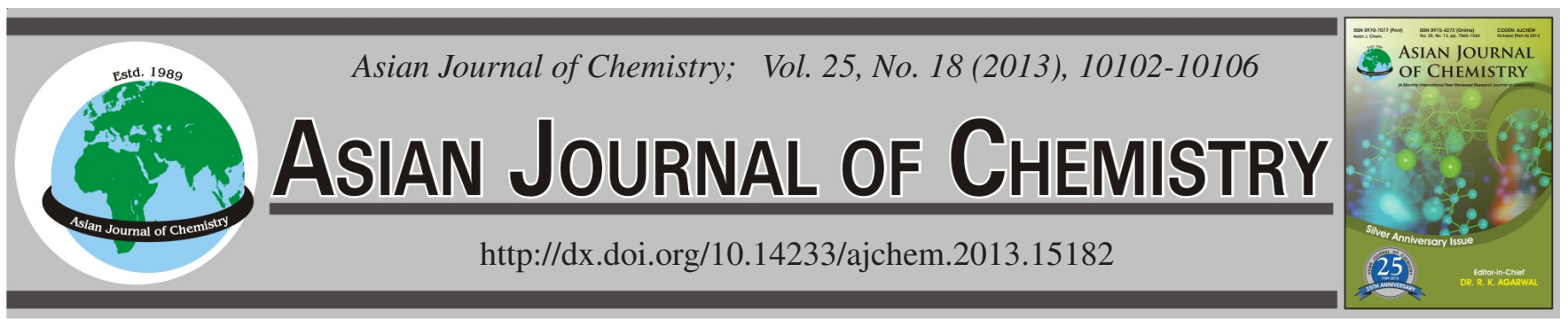

\title{
Determination of Glyoxylic Acid in Organic Electrosynthesis Using the Differential Pulse Polarography
}

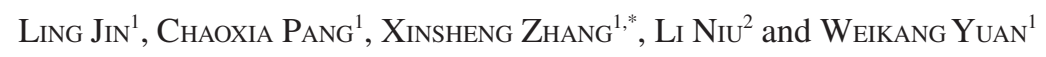

\begin{abstract}
${ }^{1}$ State Key Laboratory of Chemical Engineering, East China University of Science and Technology, Shanghai 200237, P.R. China ${ }^{2}$ State Key Laboratory of Electroanalytical Chemistry, Chang Chun Institute of Applied Chemistry, Chinese Academy of Sciences, Changchun 130022, P.R. China
\end{abstract}

*Corresponding author: Fax: +86 21 64253528; Tel: +86 21 64253469; E-mail: xszhang@ecust.edu.cn

\begin{abstract}
The differential pulse polarographic behaviour of glyoxylic acid was investigated in $10 \% \mathrm{KOH}$ solution. Glyoxylic acid displays a welldefined cathodic reduction peak at $-1.30 \mathrm{~V}(v s . \mathrm{Ag} / \mathrm{AgCl})$. The current responses were linear with the concentration of glyoxylic acid ranging from $1.35 \times 10^{-4}$ to $8.10 \times 10^{-4} \mathrm{M}$. The selectivity towards glyoxylic acid was distinct in the presence of other ions, such as $\mathrm{Ca}^{2+}$, $\mathrm{Cu}^{2+}, \mathrm{Ni}^{2+}, \mathrm{Fe}^{2+}, \mathrm{Cl}^{-}, \mathrm{SO}_{4}{ }^{2-}$ and $\mathrm{NO}_{3}{ }^{-}$. Furthermore, the peak potential for the reduction of glyoxylic acid distinctly shifted negatively about $50 \mathrm{mV}$ in the presence of tetrabutylammonium hydroxide. The peak distorted to some extent but no splitting was observed. The non-linear calibration dependencies may be approximated by the Langmuir-type equation in the presence of tetrabutylammonium hydroxide. It is necessary to use at least twice standard additions in analysis procedure. The present method was successfully applied for the fast, simple, sensitive determination of glyoxylic acid in electroreduction industrial process with and without the chemical activator.
\end{abstract}

Key Words: Glyoxylic acid, Oxalic acid, Determination, Differential pulse polarographic, Electroreduction.

\section{INTRODUCTION}

Glyoxylic acid is an important intermediate extensively uses in the perfumery, pharmaceutical and fine chemical industries ${ }^{1}$. Various industrial methods to produce glyoxylic acid have attracted the interest of many researchers. Among those methods, the electroreduction of oxalic acid to obtain glyoxylic acid has been suggested as one of the most acceptable technologies because it meets the increasing and stringent requirements for environmental protection ${ }^{2,3}$. Because the oxalic acid and glyoxylic acid have the similar structures, it has difficulty to use classic chromatogram to analyze both of these substances qualitatively and quantitatively.

Although many measurements have been applied to analyze these substances including spectrophotometry ${ }^{4,5}$, titration with Cannizzaro reaction ${ }^{6}$, chromatography ${ }^{7}$ and direct polarography methods ${ }^{8}$, these techniques may have some kind disadvantages. For example, the accuracy of the titration method is easily influenced by many factors. For the spectrophotometry method, to obtain response signal, the reaction of 2,4-dimitrophenylhydrazine with glyoxylic acid must be carried out first, because the sample has a weak or no absorption in ultraviolet or visible light. These pretreatment experiments, which need a long time and complex operation, are both required for the chromatography method and the direct polarography method ${ }^{8}$.

Electrochemical method has several advantages over other methods in that they allow faster, low cost and safer analysis. More importantly, the dropping mercury electrode (DME), as the working electrode in the testing process, the electrochemical behaviour of which is independent on its past history ${ }^{9}$, enable the reproducibility of results obtained with differential pulse polarography (DPP) technique to be very good. Although the quaternary ammonium has been widely applied in industrial electrochemical process and the polarography method has been mentioned by some researchers ${ }^{6}$. But, the effect of quaternary ammonium on the results of determination has not been studied sufficiently.

Surfactants often play an important role in the electrode reaction, not only in increasing solvability of the organic compounds but also providing specific orientation to the molecules on the electrode interface ${ }^{10}$. These molecules can give rise to adsorption layers of different thickness: monolayer, bilayer or multilayer, a complex structure ${ }^{11}$. Adsorption of surfactants on the electrode and solvability of electrochemically active compounds in micelle aggregates might significantly influence the redox potential, change transfer coefficients and diffusion coefficients of electrode processes ${ }^{12,13}$. During the process of 
electroreduction of oxalic acid, to solve the cathode deactivation, addition of small amounts of certain surfactants, such as quaternary ammonium salts and tertiary amine, is widely accepted in electrosynthesis ${ }^{3}$.

To our best of knowledge, there is little research work on the determination of glyoxylic acid using differential pulse polarographic (DPP) techniques in industrial application. Herein, in this paper, the polarographic behaviours of glyoxylic acid in the presence of oxalic acid and tetrabutylammonium hydroxide (TBAH) which used as chemical activator for electrode $^{3}$ have been studied and the method has been applied to the determination of glyoxylic acid in real electroreduction samples. The adsorption phenomenon has been observed in the presence of tetrabutylammonium hydroxide and investigated in more details. The present work holds the potential for the quantifying of glyoxylic acid.

\section{EXPERIMENTAL}

A 757 VA Computrace analyzer (Metrohm, Herisau, Switzerland) was used for all voltammetric measurements equipped with a 757 VA Computrace stand. The Metrohm Multimode Mercury electrode served as a working electrode, typically in dropping mercury electrode (DME) mode. The counter electrode was platinum wire and an $\mathrm{Ag} / \mathrm{AgCl}$ (3 M $\mathrm{KCl}$ ) electrode with a ceramic diaphragm was used as a reference electrode. Dissolved oxygen was removed by nitrogen bubbling prior to measurements. All measurements were carried out at laboratory temperature $22 \pm 1{ }^{\circ} \mathrm{C}$. DP polarograms were recorded under the conditions of a drop life of $1 \mathrm{~s}$, a scan rate of $2-10 \mathrm{mV} \mathrm{s}^{-1}$ and pulse amplitude of $+50 \mathrm{mV}$.

All the reagents and chemicals used were of analytical reagent grade. Double distilled, deionized water was used for preparation of all solutions. Standard $10 \mathrm{~g} \mathrm{~L}^{-1}$ solutions were prepared by dissolving glyoxylic acid monohydrate (97\%, AlfaAesar, American) in deionized water.

The stock $10 \%$ (w/w) solutions of $\mathrm{KOH}$ (Lingfeng chemical reagent Co., Ltd., shanghai, China) were prepared using deionized water. The mercury used in the dropping mercury electrode was obtained from Xilong chemical company, Shantou, China.

Procedures: Before use, a blank polarogram of the buffer solution was recorded in order to confirm the absence of impurities. $20 \mathrm{~mL}$ of the blank solution $(10 \% \mathrm{KOH})$ was placed in the polarographic cell. The solution was purged with a stream of nitrogen gas for $300 \mathrm{~s}$. The differential pulse polarogram for the blank solution was recorded at 1s drop time, and the scan rate was $10 \mathrm{mV} \mathrm{s}^{-1}$. The $0.05 \mathrm{~mL}$ of the stock solution of the tested compound $\left(10 \mathrm{~g} \mathrm{~L}^{-1}\right.$ glyoxylic acid) was added, $300 \mathrm{~s}$ deoxygenation was carried out using purified nitrogen gas, then the differential pulse polarogram of the tested compound was recorded under the above mentioned conditions.

The glyoxylic acid determinations were made by standard additions from -1.47 to $-1.15 \mathrm{~V}$. The optimum conditions for the analytical determination of the investigated substance by DPP were found to be: peak potential of $-1.30 \mathrm{~V}$, scan rate of $10 \mathrm{mV} \mathrm{s}^{-1}$, pulse amplitude of $+50 \mathrm{mV}$ with pulse duration of $40 \mathrm{~ms}$ at an ambient temperature of $22 \pm 1{ }^{\circ} \mathrm{C}$. The calibration curves were obtained by standard addition of the glyoxylic acid and evaluation of the peak currents.
Preparation and analysis of samples: The electroreduction has been taken in $250 \mathrm{~mL}$ cell with current density maintaining at $1500 \mathrm{~A} \mathrm{~m}^{-2}$.

A lead plate with $3.14 \mathrm{~cm}^{2}$ area was used as cathode. The cathodic electrolyte was saturated oxalic acid only and saturated oxalic acid mixed with with $0.025 \mathrm{M}$ tetrabutylammonium hydroxide, respectively. After $10 \mathrm{~h}$ electrolysis, $0.05 \mathrm{~mL}$ sample was taken from cell for determining. The $50 \mu \mathrm{L}$ solution was directly taken into a cell and a standard addition method was used for quantitative determination of glyoxylic acid.

\section{RESULTS AND DISCUSSION}

Preliminary studies: Fig. 1 shows the DPP peaks of glyoxylic acid with different concentrations. A well-defined cathode peak is observed at $-1.30 \mathrm{~V}(\mathrm{vs} . \mathrm{Ag} / \mathrm{AgCl})$ in $10 \%$ (w/w) $\mathrm{KOH}$. The polarograms represented that the peak currents were linear to the glyoxylic acid concentrations and a linear regression equation is also obtained with a slope of $561.59 \mathrm{nA} \mathrm{mmol}^{-1} \mathrm{~L}^{-1}$, an intercept of $-8.60 \mathrm{nA}$ and a correlation coefficient of 0.998 .

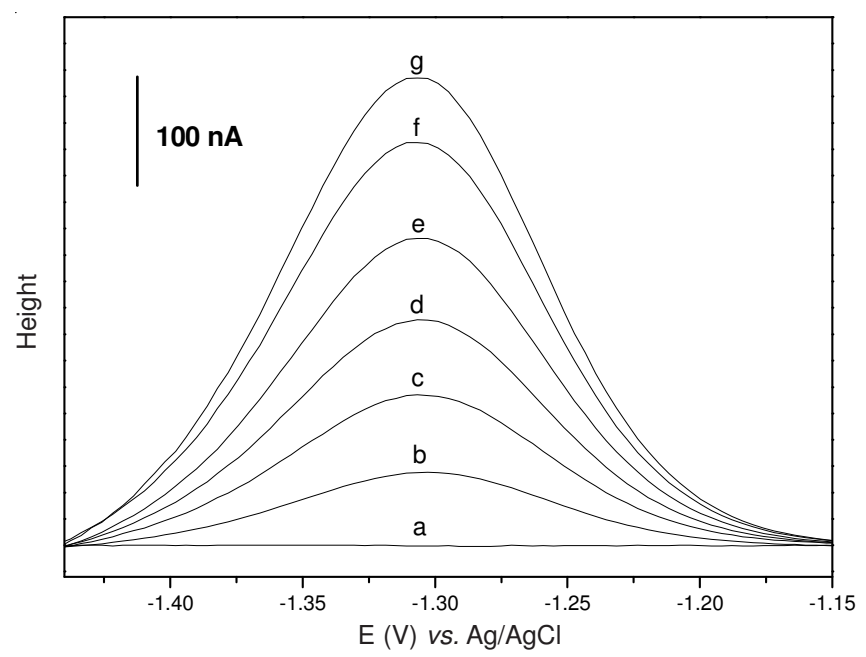

Fig. 1. Differential pulse polarogram of glyoxylic acid in $10 \% \mathrm{KOH}$. (a) $20 \mathrm{~mL}$ of $\mathrm{KOH}$ base solution. From (b-g): $1.35 \times 10^{-4}, 2.70 \times 10^{-4}$, $4.05 \times 10^{-4}, 5.40 \times 10^{-4}, 6.75 \times 10^{-4}$ and $8.10 \times 10^{-4} \mathrm{M}$ glyoxylic acid

Effect of oxalic acid: In real samples, oxalic acid is already present in solution as a feed, therefore, it is inevitable to determine glyoxylic acid in the presence of the co-existing oxalic acid and as a result, it is possible to observe its effect on accurate measurement of glyoxylic acid.

For this purpose a polarogram of samples containing both glyoxylic acid at different concentrations and saturated oxalic acid was taken. As can be seen from Fig. 2, no peak was observed for oxalic acid in $10 \% \mathrm{KOH}$ buffer solution. The reason may be that the reduction potential of carboxyl group is not in this potential range. The presence of oxalic acid does not affect negatively the peak shape and no peak distorsion or splitting was observed at the maximum concentration of oxalic acid.

It is possible to determine glyoxylic acid in the presence of maximum oxalic acid with a high accuracy. The peak current $\left(i_{p}\right)$ and concentration of glyoxylic acid yielded a linear 


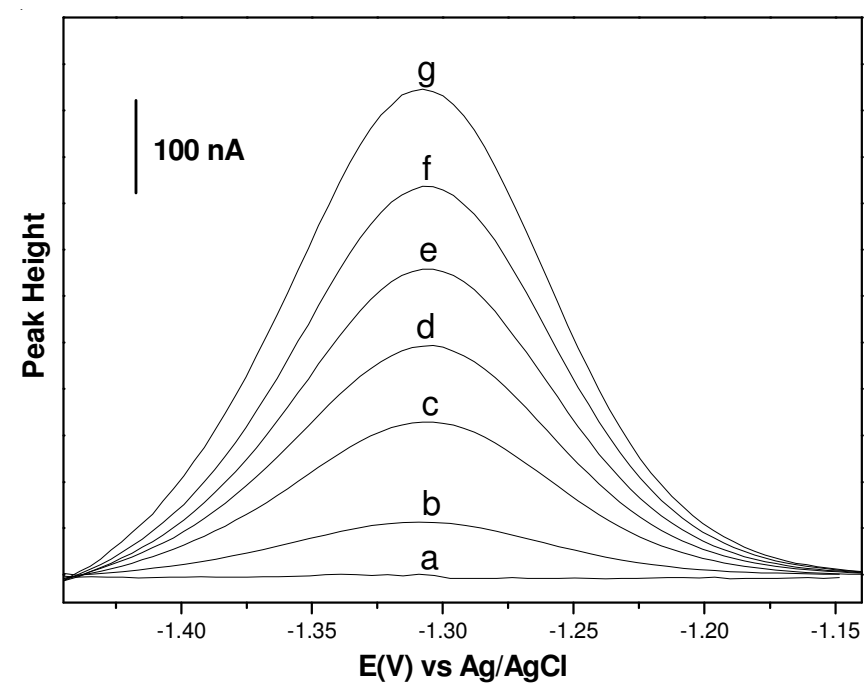

Fig. 2. Differential pulse polarograms obtained for the determination of different concentration glyoxylic acid in the presence of oxalic acid. (a) oxalic acid without glyoxylic acid. From (b-g): concentration of glyoxylic acid is $1.35 \times 10^{-4}, 2.70 \times 10^{-4}, 4.05 \times 10^{-4}, 5.40 \times 10^{-4}$, $6.75 \times 10^{-4}$ and $8.10 \times 10^{-4} \mathrm{M}$, respectively

relationship with a $\mathrm{R}^{2}$ coefficient of 0.997 , a slope of 670.16 $\mathrm{nA} \mathrm{mmol}{ }^{-1} \mathrm{~L}^{-1}$ and an intercept of $27.133 \mathrm{nA}$. The good linearity confirms that the presence of oxalic acid in cell cannot interfere with the current response signal of glyoxylic acid.

Effect of interfering ions: The influence was investigated by polarographic determining glyoxylic acid in present of some cationic and anionic species, which are commonly found in feed solutions. The interference of the various interfering ions, most of which are electro-active, e.g., $\mathrm{Pb}^{2+}, \mathrm{Cu}^{2+}, \mathrm{Ni}^{2+}$ and $\mathrm{Fe}^{2+}$ and the others inactive, e.g., $\mathrm{Ca}^{2+}, \mathrm{SO}_{4}{ }^{2-}, \mathrm{NO}_{3}{ }^{-}, \mathrm{Cl}^{-}$were studied. The amount of the interfering ions was taken at the same and fifth of that of glyoxylic acid, respectively. The ration of the peak currents (by percentage) in the presence of the interfering ions to that in their absence was used to describe the degree of interference effects. The results are summarized in Table-1.

\begin{tabular}{|c|c|c|c|c|c|c|c|c|}
\hline \multicolumn{9}{|c|}{$\begin{array}{c}\text { TABLE-1 } \\
\text { INFLUENCE OF CO-EXISTING IONS ON THE CATALYTIC } \\
\text { PEAK CURRENT OF } 100 \mu \text { M GLYOXYLIC ACID }\end{array}$} \\
\hline \multirow{2}{*}{$\mathrm{C}^{\mathrm{a}}$} & \multicolumn{8}{|c|}{ terfering ions and their influence on signal ratio (\%) } \\
\hline & $\mathrm{Ca}^{2+}$ & $\mathrm{Cu}^{2+}$ & & $\Gamma^{2+}$ & & $\mathrm{SO}_{4}^{2-}$ & & $\overline{\mathrm{Cl}^{-}}$ \\
\hline & & & & & & & & \\
\hline & 19.3 & 102.6 & 117.1 & 99.3 & 93.2 & 98.6 & 94. & 94. \\
\hline
\end{tabular}

${ }^{\mathrm{a}}$ Concentrations of interfering ions $\left(\mu \mathrm{mol} \mathrm{L} \mathrm{L}^{-1}\right)$.

Under the current polarographic conditions for the determination $0.1 \mathrm{mM}$ glyoxylic acid, ions like $\mathrm{Cu}^{2+}, \mathrm{Fe}^{2+}, \mathrm{Pb}^{2+}$ and $\mathrm{Ni}^{2+}$ did not seriously affect the glyoxylic acid peak. $\mathrm{Ca}^{2+}, \mathrm{NO}_{3}^{-}$, $\mathrm{SO}_{4}{ }^{2-}$ and $\mathrm{Cl}^{-}$are polar graphically inactive species and therefore had no notable effect on the polarographic current of glyoxylic acid. The results are coherent with the conclusions of other authors that those anions nearly has no interference during most electrochemical methods ${ }^{14,15}$.

Effect of surfactant additives: The polarogram for different concentrations of glyoxylic acid in the presence of $6.0 \times$ $10^{-5} \mathrm{M}$ tetrabutylammonium hydroxide is given in Fig. 3. It was observed that the addition of tetrabutylammonium hydroxide to $\mathrm{KOH}$ supporting electrolyte causes a shift by $50 \mathrm{mV}$

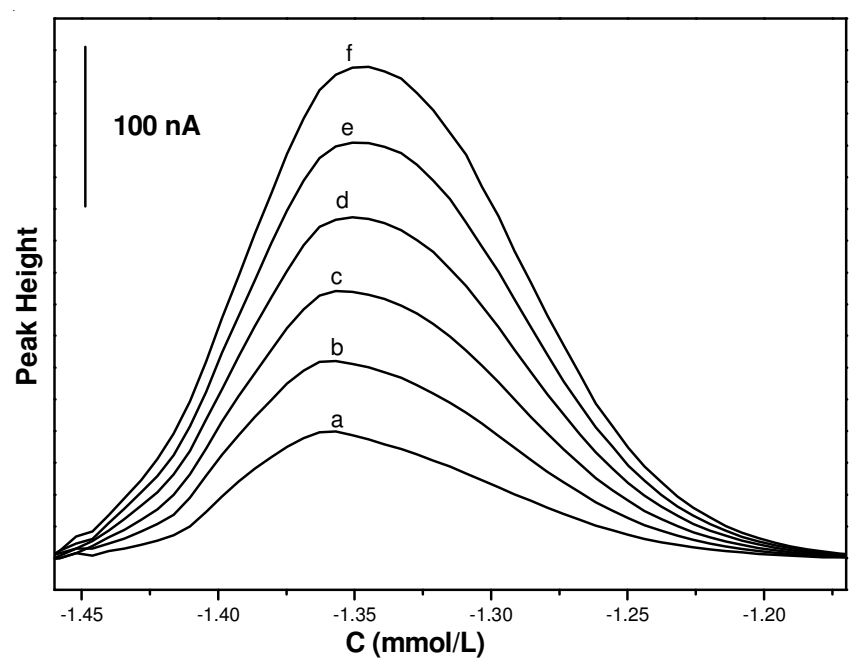

Fig. 3. Different pulse polarograms of glyoxylic acid in buffer solution containing $6 \times 10^{-5} \mathrm{M}$ tetrabutylammonium hydroxide. Glyoxylic acid: (a) $1.35 \times 10^{-4}$, (b) $2.70 \times 10^{-4}$, (c) $4.05 \times 10^{-4}$, (d) $5.40 \times 10^{-4}$, (e) $6.75 \times 10^{-4}$, (f) $8.10 \times 10^{-4} \mathrm{M}$

toward more negative potential and a litter change of peak shape. This may due to the adsorption of surfactant on the $\mathrm{Hg}$ working electrode.

The relationship between peak height and concentration of tetrabutylammonium hydroxide in supporting solution was plotted in Fig. 4. For all the straight lines in Fig. 4, coefficients of determination $\left(\mathrm{R}^{2}\right)$ were higher than 0.99 suggesting that the dependence of the peak height on the tetrabutylammonium hydroxide concentration can be expressed by the Langmuirtype (eqn. 1) equation of following form:

$$
\mathrm{i}_{\mathrm{p}}=\frac{\mathrm{abC}}{1+\mathrm{bC}}
$$

where $i_{p}$ is the maximum peak current (peak height), $C$ is the analyte concentration and $\mathrm{a}, \mathrm{b}$ are constants. These linearized forms of the Langmuir isotherms indicated that an adsorption of tetrabutylammonium hydroxide on the surface of the working electrode played an important role during the electrode process ${ }^{16}$.

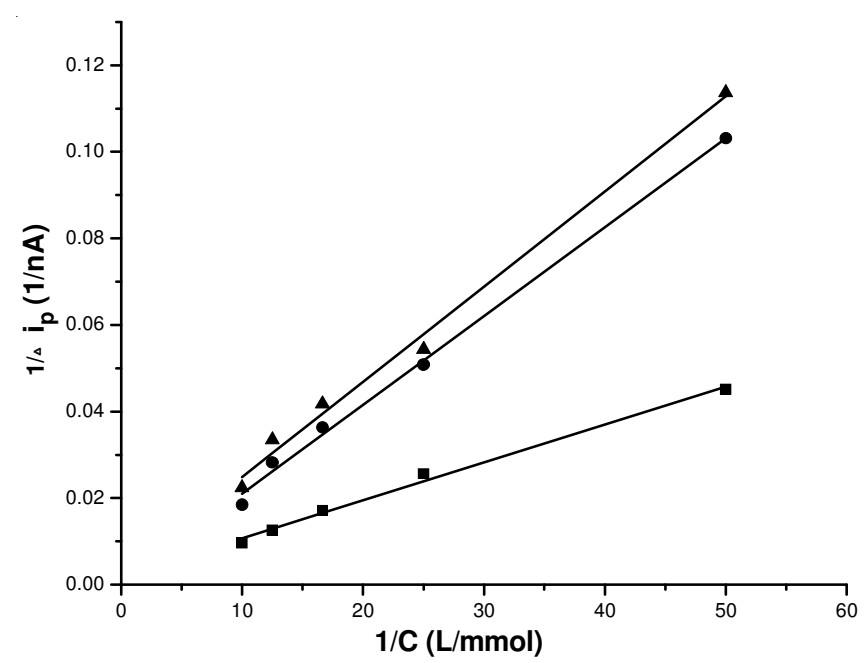

Fig. 4. Dependences of the peak increase on the concentration of tetrabutylammonium hydroxide plotted in the form of the linearized Langmuir isotherm for various concentration of glyoxylic acid: \% $0.135 \mathrm{mM}, \% 0.27 \mathrm{mM}, \% 0.338 \mathrm{mM}$ 
As well known, the adsorption phenomena can be determined by polarographic techniques sensitively ${ }^{17,18}$. Therefore, the effects of some operational parameters on the DPP peak of glyoxylic acid were studied in more details. The results showed that the peak height almost had no change with various initial potential. The equilibrating time period before the start of measurements had no effect on the peak height ${ }^{16}$. However, the peak height decreased largely with the increasing pulse time, $\mathrm{t}_{\mathrm{p}}$. Their relationship can be described by Cottrell equation as following:

$$
\mathrm{i}_{\mathrm{p}}=\frac{n \mathrm{nFAD}}{\pi^{1 / 2} \mathrm{c}^{*} \mathrm{t}^{1 / 2}}+\mathrm{i}_{\mathrm{C}}+\mathrm{i}_{\mathrm{ad}}
$$

where $i_{p}$ is the maximum peak current in unit $A$ (peak height), $\mathrm{i}_{\mathrm{c}}$ is double layer current in unit $\mathrm{A}, \mathrm{i}_{\mathrm{ad}}$ is the current causing by adsorption of reactant in unit $\mathrm{A}, \mathrm{c}^{*}$ is the initial concentration of reducible analyte in $\mathrm{mol} \mathrm{L}^{-1}, \mathrm{n}$ is number of electrons, $\mathrm{F}$ is faradic constant equating $96485 \mathrm{C} \mathrm{mol}^{-1}$, A is area of electrode in $\mathrm{cm}^{2}$, D is diffusion coefficient for reactant in $\mathrm{cm}^{2} \mathrm{~s}^{-1}$ and $\mathrm{t}$ is time in $\mathrm{s}$.

As can be seen from Fig. 5, the peak height decreased observably with increasing the pulse time, $t_{\mathrm{p}}$. The plots of $\mathrm{i}_{\mathrm{p}}-\mathrm{t}_{\mathrm{p}}{ }^{-0.5}$ exhibited a non-zero intercept in the supporting electrolyte containing tetrabutylammonium hydroxide of different concentrations which proved the presence of the reactant adsorption ${ }^{17}$. With larger concentration of tetrabutylammonium hydroxide, the intercept increases, indicating that the presence of tetrabutylammonium hydroxide has a great influence on the adsorbance of reactant. And the slopes increased with the concentration of tetrabutylammonium hydroxide implying that the cationic surfactant tetrabutylammonium hydroxide maybe has a direct effect on glyoxylic acid transport parameters, notably on the diffusion coefficient.

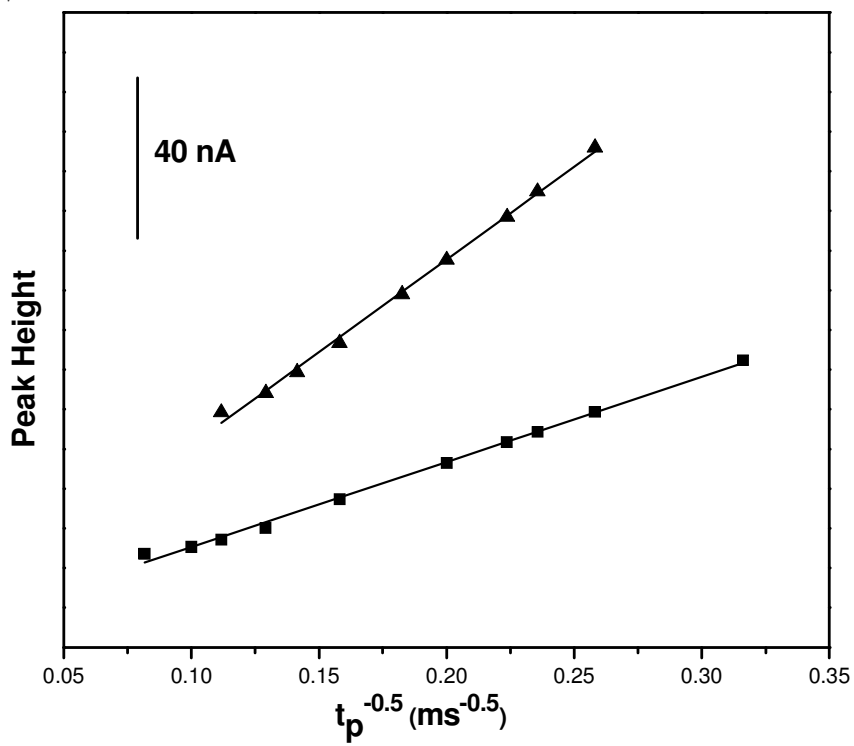

Fig. 5. Effect of the pulse time on the peak height -the $\mathrm{i}_{\mathrm{p}} v s . \mathrm{t}_{\mathrm{p}}^{-0.5}$ dependence for various concentration of tetrabutylammonium hydroxide: $\% 0.1$ $\mathrm{mM} ; \% 0.06 \mathrm{mM}$. Concentration of glyoxylic acid $0.135 \mathrm{mM}$

Based on the data from Fig. 6, it can be observed that the presence of tetrabutylammonium hydroxide has a remarkable effect on a linearity of the glyoxylic acid calibration curve, since the DPP peak shape has been distorted in the presence of tetrabutylammonium hydroxide. Generally, it has to find a model calibration curve to subtract the effect of additives and evaluate the procedures for non-linear calibration functions ${ }^{16}$. In spite of the adsorption mechanism may be complex, it still can be assumed that the curves abide by certain adsorption isotherms ${ }^{18}$. As seen in Fig. 6, when the Langmuir-type equation was applied to model the calibration curve, a good fit was achieved. The Langmuir equation is a rational function which only contains two parameters, so it is necessary to additive twice standard solution during the determination process of an unknown sample.

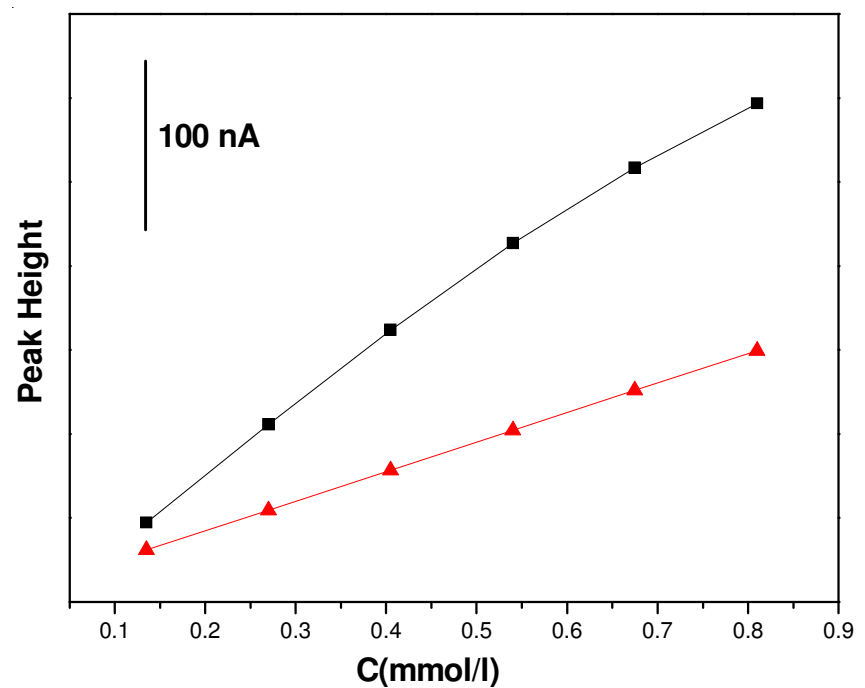

Fig. 6. Calibration curves in the absence (\%) and in the presence (\%) of tetrabutylammonium hydroxide $(0.1 \mathrm{~mol} / \mathrm{L})$

Application to real electrosynthesis samples: The quaternary ammonium salts have been widely used as electrolysis additive because of they can accelerate the electro reactions. However, the polarography method has not been applied in determining such mixed products. Most analysis procedures were completed through HPLC which needs much more pretreatment and post-treatment time. The present method was simple to determine glyoxylic acid in several electrosynthesis samples with or without adding quaternary ammonium during electroreduction process. For $\mathrm{N}=10$ and $95 \%$ confidence interval, the electrolysis results obtained in the absence and presence of the additive are shown in Table-2, respectively.

TABLE-2

DETERMINATION OF GLYOXYLIC ACID IN PRODUCT OF ELECTROREDUCTION FROM OXALIC ACID

\begin{tabular}{lcccc}
\multicolumn{1}{c}{$\begin{array}{c}\text { Synthetic sample } \\
\left(\mathrm{g} \mathrm{L}^{-1}\right)\end{array}$} & $\overline{\mathrm{X}}$ & $\mathrm{S}$ & $\overline{\mathrm{X}} \pm \frac{\mathrm{ts}}{\sqrt{\mathrm{N}^{\mathrm{b}}}}$ & $\begin{array}{c}\mathrm{RSD} \\
(\%)\end{array}$ \\
\hline $\begin{array}{l}\text { Electroreduction of } \\
\text { products with oxalic } \\
\text { acid only }\end{array}$ & 25.726 & 0.723 & $25.726 \pm 0.517$ & 2.81 \\
$\begin{array}{l}\text { Electroreduction of } \\
\text { products with oxalic } \\
\text { acid and TBAH }\end{array}$ & 37.234 & 0.735 & $37.234 \pm 0.525$ & 1.97 \\
\hline $\begin{array}{l}\text { a } \\
\text { Concentration of } \\
\text { interval, } \mathrm{t}=2.262 .\end{array}$ & & & & \\
\hline
\end{tabular}


To demonstrate the validity of this method, the same procedure has been applied to all samples and the same concentration $\left(10 \mathrm{~g} \mathrm{~L}^{-1}\right)$ of glyoxylic acid has been used as standard solution. The results for two synthetic samples are given in Table-2. As can be seen from the Table-2, the additive accelerated the electroreduction markedly and resulted that the glyoxylic acid was much more than that obtained from no additive adding electrolyte. The results from both samples are $25.726 \pm 0.517$ and $37.234 \pm 0.525 \mathrm{~g} \mathrm{~L}^{-1}$ with the relative standard deviations of 2.81 and $1.97 \%$, respectively. The results are satisfactorily accurate and precise.

\section{Conclusion}

With the proposed method glyoxylic acid can be detected with improved sensitivity and resolution by differential pulse polarography. There is no need for any prior steps which are tedious, time-consuming and also polluting. The differential pulse polarography has proved to be a simple and highly sensitive method presented for the quantitative determination of glyoxylic acid to allow the accurate determination in electrosynthesis product. The polarographic behaviour of glyoxylic acid in the presence of different ions was obtained and the well-defined peak was observed in the presence of tetrabutylammonium hydroxide surfactant. Thus, the present method could possibly be applied for the determination of glyoxylic acid in the presence of surfactant additive as well as for quality control laboratories.

\section{ACKNOWLEDGEMENTS}

This work was supported by the open foundation of the State Key Laboratory of Electroanalytical chemistry (Changchun Institute of Applied Chemistry, Chinese Academy of Science).

\section{REFERENCES}

1. J. Ochoa, A. De Diego and J. Santa-Olalla, J. Appl. Electrochem., 23, 905 (1993).

2. J. Li, X. Hu, Y. Su and Q. Li, Chem. Eng. Sci., 62, 6784 (2007).

3. Y. Zhou, X. Zhang, Y. Dai and W. Yuan, Chem. Eng. Sci., 58, 1021 (2003).

4. F. Goodridge, K. Lister, R. Plimley and K. Scott, J. Appl. Electrochem., 10, 55 (1980).

5. G. Pierre, M.E. Kordi and G. Cauquis, Anal. Chim. Acta, 185, 341 (1986).

6. G. Pierre, M. El Kordi, G. Cauquis, G. Mattioda and Y. Christidis, J. Electroanal. Chem., 186, 167 (1985).

7. S.-P. Chen, T. Huang and S.-G. Sun, J. Chromatogr. A, 1089, 142 (2005).

8. J. Maslowska, J. Duda and A. Witusik, Fresenius J. Anal. Chem., 355, 154 (1996).

9. Ü.T. Yilmaz and G. Somer, J. Electroanal. Chem., 624, 59 (2008).

10. P.G. Westmoreland, R.A. Day and A.L. Underwood, Anal. Chem., 44, 737 (1972).

11. M.J. Rosen, Adsorption of Surface-Active Agents at Interfaces: The Electrical Double Layer. Surfactants and Interfacial Phenomena, Wiley, New York, edn. 2 (1978).

12. R.M. Kotkar and A.K. Srivastava, Anal. Sci., 24, 1093 (2008).

13. M. Stadiober, K. Kalcher, G. Raber and C. Neuhold, Talanta, 43, 1915 (1996).

14. G. Somer, S. Sezer, M. Dogan, S. Kalayci and O. Sendil, Talanta, 85, 1461 (2011).

15. R. Inam, E.Z. Gülerman and T. Sarigül, Anal. Chim. Acta, 579, 117 (2006).

16. P. Janos and V. Synek, Talanta, 66, 188 (2005).

17. H.P. van Leeuwen, J. Buffle and M. Lovric, Pure Appl. Chem., 64, 1015 (1992).

18. H.P. van Leeuwen, R. Cleven and J. Buffle, Pure Appl. Chem., 61, 255 (1989).

19. R. Kalvoda, W. Anstine and M. Heyrovský, Anal. Chim. Acta, 50, 93 (1970). 